\title{
Evaluation of the anti-pyretic potential of Orthosiphon stamineus Benth standardized extract.
}

\begin{abstract}
The anti-pyretic activity of a standardized methanol/water (50/50) extract of Orthosiphon stamineus Benth. (SEOS) was investigated for its effect on normal body temperature and yeast-induced pyrexia in Sprague Dawley (SD) rats. The SEOS showed no effect on normal body temperature. Doses of 500 and $1000 \mathrm{mg} / \mathrm{kg}$ body weight of SEOS significantly reduced the yeast-induced elevation in body temperature. This effect persisted up to $4 \mathrm{~h}$ following the administration of the extract. The anti-pyretic effect of SEOS was comparable with that of paracetamol (acetaminophen in U.S) $(150 \mathrm{mg} / \mathrm{kg}$ p.o.), a standard anti-pyretic agent. HPLC study revealed that rosmarinic acid, sinensetin, eupatorin and tetramethoxyflavone were present in SEOS in the amounts of $7.58 \%, 0.2 \%, 0.34 \%$ and $0.24 \%$ respectively. The LD 50 of the extract in rats was higher than $5000 \mathrm{mg} / \mathrm{kg}$ body weight. Therefore, the present study ascertained that SEOS possesses a significant anti-pyretic activity.
\end{abstract}

Keyword: 3'-hydroxy-5,6,7,4'-tetramethoxyflavone; Antipyretic effect; Eupatorin; Orthosiphon stamineus; Rosmarinic acid; Sinensetin. 